\title{
Mammalian sex determination: a molecular drama
}

\author{
Amanda Swain ${ }^{1,2}$ and Robin Lovell-Badge ${ }^{1,3}$ \\ ${ }^{1}$ Division of Developmental Genetics, Medical Research Council (MRC), National Institute for Medical Research, \\ London NW7 1AA, UK; ${ }^{2}$ Section of Gene Function and Regulation, Chester Beatty Laboratories, Institute of Cancer \\ Research, London SW3 6JB, UK
}

Our knowledge of mammalian sex determination is based on two main areas of study. First, the characterization of the biological events that determine the sexual development of the individual, including patterns of gene expression, and second, the study of genetic mutations in humans and mice that lead to abnormal sexual phenotypes. In the search for molecular components of this process, the identification of genes in loci involved in human disease has been especially fruitful. Serendipity has also played a hand, where in several cases targeted mutations in mouse genes, being studied for other reasons, have led to unexpected sex reversal phenotypes. The collection of molecular candidates implicated in sex determination is now quite extensive. We are not able to fit all of these into simple pathways, where one gene acts on the next and so on in a linear fashion, as seems possible in the invertebrate model organisms, Caenorhabditis elegans and Drosophila. In part this is due to gaps in our knowledge, as we are clearly missing several key components, but it is looking increasingly likely that the system is much better described as a network of factors. In fact, the story so far is like some partly recovered script for a play. Thus some gene products are main characters with roles at several different stages, some act as a chorus, in a combinatorial fashion with others, whereas a few play a critical role in one scene and then disappear. The mechanism presumably evolved to be delicately poised to respond to the initial trigger to be male or female and then to amplify this decision while avoiding development of intersex phenotypes. It is therefore likely to be a system full of back-ups and functional redundancy. The complexity may also follow from the relatively late embryonic stage at which the decision is reached. This means that events occurring in one cell lineage have to be coordinated with others in the context of a developing organ and eventually the whole organism. We review here the story that is beginning to emerge, focusing mostly on the set of transcription factors that appear to play important leading and supporting roles.

${ }^{3}$ Corresponding author.

E-MAIL rlovell@nimr.mrc.ac.uk; FAX 0181-906-4477.
In mammals, the genetic sex of the embryo is established at fertilization with the inheritance of an X or Y chromosome from the father. However, the sex-determining process is set in motion only during the period of organogenesis when the gonads develop. The Y chromosome, through the testis-determining gene Sry, acts dominantly to trigger differentiation of testes from the indifferent gonads (or genital ridges) that would otherwise develop as ovaries (Gubbay et al. 1990; Sinclair et al. 1990). Sry is the only gene needed from the Y chromosome to establish male development, as shown by transgenic experiments where XX mice carrying the Sry gene develop as males (Koopman et al. 1991). Conversely, mutations in Sry can lead to relatively normal female development of XY mice and humans (Gubbay et al. 1992; Hawkins et al. 1992). Once the gonads begin to differentiate as testes or ovaries, they secrete factors, notably anti-Mullerian hormone (AMH, otherwise known as Mullerian-inhibiting substance, or MIS) and testosterone from the testes, which determine the sexual development of the rest of the embryo. There are many steps in this process that, when affected, will give rise to different degrees of sex reversal. The challenge has been to correlate the phenotype of affected individuals with the appropriate step and translate this into a molecular mechanism.

\section{Early gonad development: setting the stage}

The mammalian gonad forms within the developing urogenital system, which itself derives from the intermediate mesoderm that runs the length of the embryo on either side of the midline (axial and paraxial) structures. This system is divided into three regions: pronephros, mesonephros, and metanephros, which develop anterior to posterior along the nephric or Wolffian duct (Fig.1). The pronephros is vestigial in mammals but the mesonephros can serve as a primitive kidney during embryogenesis in some species. The definitive kidney is the product of the interaction between the metanephric mesenchyme at the posterior end of the urogenital system and the ureteric bud, which grows out of the Wolffian duct. A second duct, the paramesonephric or Mullerian duct, originates within each mesonephros by in- 


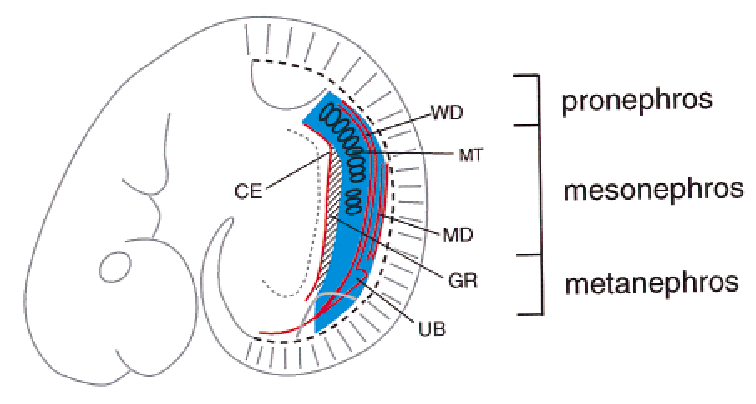

Figure 1. Structure of the urogenital system. Schematic of the mouse urogenital system at $10.5 \mathrm{dpc}$. Epithelial structures are shown in red, mesenchymal structures are shown in blue, and the striped region denotes the genital ridge. (WD) Wolffian duct; (MT) mesonephric tubules; (MD) Mullerian duct; (UB) ureteric bud; (CE) coelomic epithelia.

vagination of the coelomic epithelium. This duct runs parallel to the Wolffian duct but turns toward the midline at the posterior end of the mesonephros and fuses with the companion duct. The gonads arise as a thickening of the ventrolateral surface of each mesonephros and, in the mouse, they are first visible at $\sim 10$ days postcoitum (dpc). The genital ridges are composed of somatic cells derived from the mesonephros and primordial germ cells that have migrated, via the hindgut and mesonephros, from extraembryonic mesoderm at the base of the allantois (Ginsburg et al. 1990).

Mutation studies have identified several genes essential for early gonad development. The role of these in sex determination, however, is not always clear. The consequences of the mutations are often too severe to address whether the products of these genes are involved in upstream events, such as Sry regulation, whether they act as partner factors, or whether they have critical roles downstream in the control of sex-specific gene regulation. Indeed, they could act at all these levels. One such gene encodes steroidogenic factor 1 (SF1) (Lala et al. 1992; Morohashi et al. 1992; Honda et al. 1993). SF1 is a member of the subfamily of nuclear receptors, the orphan receptors, for which no clear activating ligand has been found. This transcription factor has a DNA-binding domain composed of two zinc fingers, which are highly conserved among mammals. Also conserved is a domain at the carboxyl terminal of the zinc finger region, which is similar to that found in a subset of nuclear receptors that interact as monomers with an AGGTCA motif in the DNA. In the putative ligand binding/dimerization domain, two regions thought to be involved in transcriptional activation are conserved in $\mathrm{SF} 1$; a proline-rich domain and an AF-2 type domain similar to that found in other receptors (for review, see Parker 1998). SF1 was first identified as an activator of genes involved in steroid biosynthesis in different steroid hormone producing cells (Ikeda et al. 1993; Morohashi et al. 1993). Expression studies in mice showed that SF1 is present during embryo development in regions associated with endocrine function such as gonads, adrenals, pituitary, and hypothalamus (Hatano et al. 1994; Ikeda et al. 1994; In- graham et al. 1994; Morohashi et al. 1994). Mice with a homozygous disruption of the $S f 1$ gene lack gonads and adrenals and have impaired gonadotrope function and ventromedial hypothalamic structure (Ingraham et al. 1994; Luo et al. 1994; Ikeda et al. 1995; Sadovsky et al. 1995; Shinoda et al. 1995). These studies show that this factor has an essential role as a regulator of endocrine differentiation at multiple levels.

The gonads of embryos lacking $S f 1$ cease to develop between 11-11.5 dpc and degenerate via apoptosis (Luo et al. 1994). The adrenal glands also fail to form. However, the essential role of SF1 in the development of both these organs remains unclear. The genital ridges begin to form and are colonized by the germ cells, which must still receive the correct signals to direct their migration. SF1 is therefore not involved in specifying the initial development of the gonad along the urogenital system, or the acquisition of early gonadal cell identity. Rather, SF1 seems to be necessary for the differentiation and/or the maintenance and growth of the somatic cells already present in the early indifferent gonad. Sf1 gene expression is specifically associated with the gonad and the adrenal as they arise and is a good marker of these cells. Careful expression studies in the rat using an antibody to SF1 have shown a population of positive cells present just before the gonad can be observed morphologically. This group of cells will later separate to form the somatic cells of the gonad and the cortical cells of the adrenal (Hatano et al. 1996; Morohashi 1997). This is in agreement with the proposal that these two organs are derived from the same primordia. The origin of these adrenogenital cells is still not well defined but they could be derived from coelomic epithelia, mesonephric mesenchyme, or mesonephric ducts (Fig. 1). Advances are being made with studies in which immature gonadal cells are labeled with lineage tracers and the fate of these cells is followed after development of the gonad in vitro. These studies show that the coelomic epithelium, which lines the coelomic cavity, contributes to somatic cells of the gonad, including Sertoli cells (Karl and Capel 1998). Further studies will define if the underlying mesenchyme or the ducts also contribute to the cells of the early gonad, although the Pax2 mutant phenotype (see below) suggests that the ducts are not necessary.

Genes that are important in the differentiation of the intermediate mesoderm and the urogenital system as a whole will generally have a role in early gonad development. This group of genes is characterized by their mutant phenotypes, which show defects in both early kidney and gonad development. Lim1, which encodes a member of the LIM class of homeobox proteins, is one such gene. Mice homozygous for deletions in Lim1 have no kidneys or gonads (Shawlot and Behringer 1995). The gene is expressed during early urogenital development in the mesonephric duct and tubules and in the ureteric bud in the metanephros (Fujii et al. 1994). Interestingly, PAX2, a member of the paired-box family of transcription factors, is found in much the same regions although it is also found in the mesenchyme. However, whereas the Pax2-deficient mice lack kidneys and urogenital 
ducts, the gonads and adrenals do form (Torres et al. 1995). Both Lim1 and Pax2 are thought to have essential functions during the very early phases of kidney development (Vainio and Muller 1997), but the role of Lim1 in early gonad development has not been studied in any detail.

The Wilm's tumor-associated gene (WT1) has also been implicated in early gonad and kidney development. This gene is complex as it encodes a variety of protein products with different functions. The WT1 gene in mouse and man is comprised of 10 exons and there are four major species of RNA generated by two different alternative splicing events (Reddy and Licht 1996, and references therein). In addition, there are two alternative translation start points and post-translational RNA editing leads to isoforms that differ in one residue (Sharma et al. 1994). There are, therefore, 16 possible forms of the protein. Overall there are several functional domains within the protein (Fig. 2). The domain at the carboxyl terminus contains four DNA-binding zinc fingers homologous to those of the early growth response family of transcription factors (EGR). Isoforms that are otherwise identical, but for the presence or absence, through alternative splicing, of three amino acids (lysine, threonine, and serine, KTS) between the third and fourth zinc fingers, have different affinity for DNA. A transregulatory domain, which is proline and glutamine rich, has been mapped to the amino terminus. This suggests that WT1 can act as a transcription factor. Studies performed in vitro with some forms of WT1 show that it can regulate transcription in different ways. In certain contexts it binds DNA and can act as either a repressor or an acti-

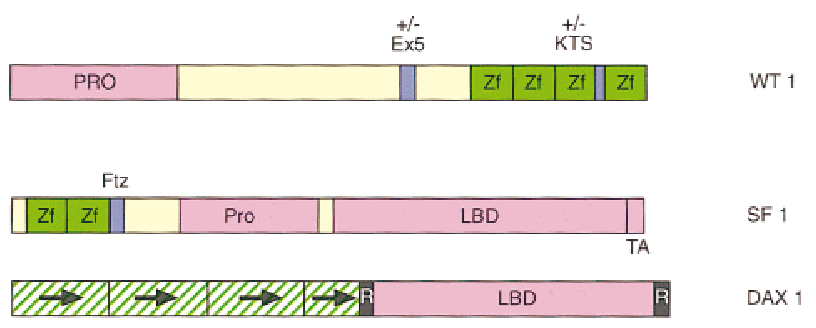

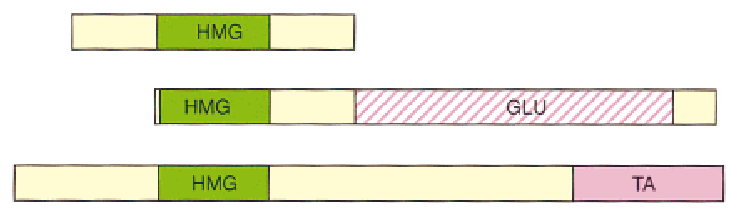

SRY (h)

$\operatorname{SRY}(\mathrm{m})$

Figure 2. Protein structure. Shown are the structural domains found in several proteins involved in sex determination. (PRO) Proline-rich domain; (Ex5) exon 5, whose presence in WT1 depends on alternative splicing; (Zf) zinc finger DNA-binding domain; (KTS) whose presence in WT1 depends on alternative splicing; (Ftz) Ftz box domain involved in SF1 binding DNA as a monomer; (TA) transcriptional activating domain; $(\mathrm{R})$ repressor domain; (HMG) HMG box DNA-binding domain; (GLU) glutamine-rich domain. In the case of Sry, the structure of the mouse $(\mathrm{m})$ and human $(\mathrm{h})$ proteins are shown. vator; in others it may work as a coactivator where DNA binding is not required (Reddy and Licht 1996, and references therein; Nachtigal et al. 1998). In addition, immunocytochemical studies have shown that the + KTS isoform of WT1 colocalizes with proteins involved in RNA splicing, suggesting a role in RNA processing (Larsson et al. 1995). It appears therefore that WT1 can regulate cell function at several different levels.

WT1 mutations are involved in three different but related syndromes in humans. Heterozygous deletions of the gene are associated with mild genitourinary malformations and will predispose to childhood kidney tumors. In Denys-Drash syndrome, heterozygous missense mutations in the zinc finger DNA-binding domain of WT1 lead to severe and more frequent urogenital malformations (Pelletier et al. 1991). It is thought that these mutant forms of the protein act as dominant negatives that cannot bind DNA and interfere with wild-type WT1 action. XY individuals with Denys-Drash syndrome are more affected than XX and sometimes show ambiguous or female genitalia, suggesting that the gene is involved in male urogenital development. Consistent with this, $\mathrm{XY}$ patients with Frasier syndrome develop as females and display urogenital malformations. Analysis of patients has shown that donor splice mutations in WT1 with loss of the $+\mathrm{KTS}$ isoform are associated with this syndrome (Barbaux et al. 1997). This may indicate a critical RNA processing function for the protein in sex determination.

In contrast to humans, mice carrying a heterozygous deletion in the Wt1 gene do not develop tumors or have genitourinary malformations. Homozygous deletions of $W t 1$, however, lead to an absence of gonads and arrested kidney development (Kreidberg et al. 1993). During embryogenesis, the Wt1 gene is expressed throughout the intermediate mesoderm at $9.5 \mathrm{dpc}$ and later in the gonad and the differentiating mesenchyme in the metanephros. In the kidney, WT1 is required for ureteric growth although it is not expressed in the ureteric bud but in the metanephric mesenchyme (Pritchard-Jones et al. 1990). Recent studies have shown that WT1 is also important for the formation of most mesonephric tubules that depend on a mesenchyme to epithelial transition (Sainio et al. 1997). Inductive events between mesenchyme and epithelia have not been well characterized in the developing gonad, however, it may be that WT1 similarly regulates inductive signals from the mesenchyme to the coelomic epithelia in this organ. If so, it may be responsible for the growth of the genital ridge by directing the ingression of cells from the coelomic epithelium. As these cells contribute to Sertoli cells (Karl and Capel 1998), mutations in Wt1 could lead to sex reversal simply because of a deficiency of their precursors.

Mice deficient for the gene encoding EMX2, a transcription factor containing a homeobox domain, also show impaired gonadal and kidney development (Miyamoto et al. 1997). At $11.5 \mathrm{dpc}$, the mutant embryos have poorly developed gonads and the mesonephric tubules and Wolffian ducts degenerate. The analysis of the kidney defect suggests that EMX2 is necessary for the re- 
sponse of the ureteric bud to the signal from the mesenchyme. This would place this gene downstream of WT1 in the cascade of kidney development. Consistent with this, Wt1 expression is unaffected in the $E m \times 2$ mutants. However, the role of Emx2 in gonad development is still not clear. Emx2 is expressed in the genital ridge as well as the Wolffian duct, mesonephric tubule, and coelomic epithelia. Interestingly, the Emx2-deficient mice show normal adrenal development. This would suggest that the gonadal defect in these mice can not be due to a failure in the SF1 positive cells of the gonad, which are shared with the adrenal. Perhaps Emx2 is required to sustain the coleomic epithelium and gonadal development is more sensitive to the state of the epithelium than the adrenals.

A recent report on the mouse $M 33$ gene, which is related to the Drosophila polycomb group (PcG) genes, has suggested that it is involved in the early development of the gonad but in a different way to the factors mentioned above. Mice carrying a disrupted M33 gene show retarded gonad development (Katoh-Fukui et al. 1998). Unlike the case for disruptions in the genes described above, these retarded gonads do give rise to adult organs although they are not completely normal and the phenotype is variable. The XY animals showed different degrees of sex reversal. It is not clear what stage of testis development is affected in the M33-mutant mice. Analysis of early testicular markers in these mice will establish whether this gene acts upstream or downstream of Sry. The PcG proteins in Drosophila are thought to be part of a system that maintains the pattern of expression of homeotic genes, which are responsible for providing positional information to the embryo. The role of polycomb proteins is to repress gene expression by forming a multimeric complex that compacts chromatin making it inaccessible to transcription factors. Loss-of-function mutations in polycomb lead to posterior homeotic transformations. Consistent with this, the M33-deficient mice do show homeotic transformations in the structure of their skeleton (Core et al. 1997; Bel et al. 1998; KatohFukui et al. 1998). It is possible that these mice also have a defect in positional information during gonad development. The cells of the mesonephros without M33 may have acquired partial metanephric identity and therefore gonad development is affected. Alternatively, there may be a defect in the timing of the development of the gonad with respect to the timing of the differentiation of the rest of the urogenital system. The homeotic gene targets for M33 in the urogenital system are not known, but different Hox genes are expressed along the urogenital system (Dolle et al. 1991).

\section{The bipotential gonad and the sex determining switch: the critical scene}

There are essentially three different cell lineages present in the gonad as well as the germ cells. Each lineage has a bipotential fate depending on the sex of the organ in which they are found. The supporting cell lineage will give rise to Sertoli cells in the testis and follicle cells in the ovary. These cells surround the germ cells and provide an appropriate growth environment. The steroidogenic cell lineage produces the sexual hormones that will contribute to the development of the secondary sexual characteristics of the embryo. In the male these are the Leydig cells and in the female, the theca cells. The connective cell lineage will contribute to the formation of the organ as a whole. Early testis development is characterized by the formation of testicular cords that contain Sertoli and germ cells, with the Leydig cells excluded to the interstitium. The connective cell lineage is a major contributor to cord formation as the peritubular myoid cells surround the Sertoli cells and together they lay down basal lamina. The testis is also characterized by rapid and prominent vascularization. Organization of the ovary takes places later than that of the testis and is less structured, with the connective tissue lineage giving rise to stromal cells and with no myoid cell equivalent (Fig. 3).

The gonad initially develops in a non-sex-specific manner, being morphologically identical in $\mathrm{XX}$ and $\mathrm{XY}$ embryos up until $\sim 12.0 \mathrm{dpc}$. However, at $\sim 10.5-11 \mathrm{dpc}$, Sry begins to be expressed in the male genital ridge and acts to initiate testis development. In the mouse, Sry is expressed in the genital ridge as a wave from anterior to posterior that lasts about a day and a half so that each cell sees it for a few hours only (Hacker et al. 1995; Jeske et al. 1995; Swain et al. 1998). Studies on chimeric mice derived from XX and XY cells showed that almost all of the Sertoli cells in the testes were XY whereas other lineages showed no chromosomal bias (Palmer and Burgoyne 1991). The action of SRY is therefore thought to trigger differentiation of the Sertoli cell lineage in the testis. Once SRY triggers Sertoli cells they in turn direct the differentiation of the rest of the cell types in the testis. Therefore the decision of sex determination is essentially one of cell fate: SRY triggers Sertoli cell fate in a cell that would otherwise become a follicle cell.

The switch in cell fate brought about by SRY is likely to occur at the level of transcriptional control. The SRY protein contains an HMG box type of DNA-binding domain similar to that found in other transcription factors. For SRY, this appears to be the most critical part of the protein. With one exception, all mutations found in $S R Y$, in cases of human XY female sex reversal, cluster in this region (Harley et al. 1992). In addition, the HMG box domain is relatively well conserved, unlike the rest of the protein which is so dissimilar between all but closely related species that it is often impossible to even align (Tucker and Lundrigan 1993; Whitfield et al. 1993) (Fig. 2). HMG box domains are known to bind DNA in the minor groove and to bend the DNA to acute angles. Moreover, binding affinity and the angle of the bend can be affected independently by sex reversing mutations in the box (Pontiggia et al. 1994). This suggests that an important molecular mechanism underlying SRY action is to change the chromatin configuration and therefore affect transcription by influencing neighboring interactions between DNA and proteins.

The transient nature of Sry expression in the gonad 


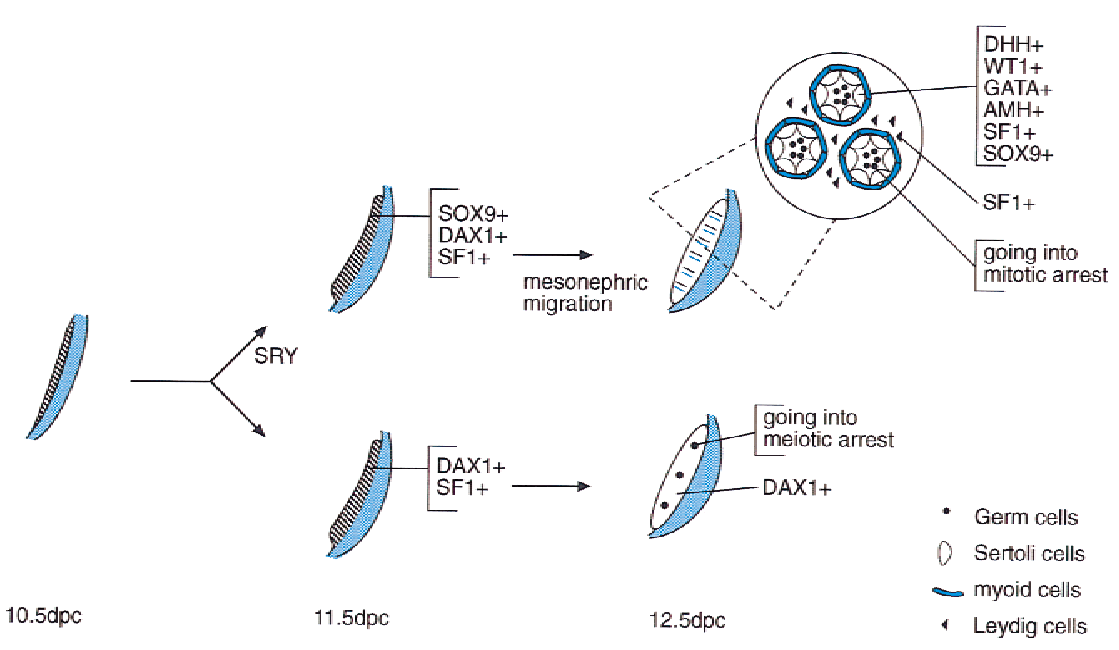

Figure 3. Morphological changes in the gonad during differentiation. Shown are the molecular and structural changes that occur during differentiation of the mouse gonad along the male (top) and the female (bottom) pathway. The stages of embryo development that are depicted are indicated at the bottom. The genital ridge is shown as a striped structure; the mesonephros is shown in blue. Before $10.5 \mathrm{dpc}$ the genital ridge of the embryo is identical between males and females. After the action of SRY, molecular differences in the gonad can be observed, as depicted at $11.5 \mathrm{dpc}$. Morphological differences between the testis and the ovary can be observed at $12.5 \mathrm{dpc}$. The structure of testicular cords, which is a consequence of migration of mesonephric cells, is shown as part of the male pathway. The different cell types of the testis and ovary are indicated, as are the genes expressed therein. Myoid cells, indicated in blue, are thought to derive from the mesonephric contribution. The different fate of germ cells between the testis and the ovary is shown. suggests that it acts as a switch toward Sertoli cell fate but that it is not involved in the maintenance of cell identity or cell function. Therefore, SRY must in some way activate other genes that are involved in defining and maintaining Sertoli cell identity. A candidate for this type of downstream gene is Sox9. Its protein product is related to SRY as it contains a similar HMG box domain. However, it also has a strong transactivation domain at its carboxy terminus (Sudbeck et al. 1996). In addition, the entire protein is highly conserved throughout vertebrate evolution, unlike SRY, which is mammal specific. Expression studies in the mouse have shown that Sox 9 is present at low levels in both male and female genital ridges when the gonad first develops. However, by $11.5 \mathrm{dpc}$, it has been upregulated in the male and turned off in the female gonad. By $12.5 \mathrm{dpc}$ it is clear that Sox9 is expressed in Sertoli cells, where it persists throughout life, whereas it is not seen at all in the ovary (Kent et al. 1996; Morais et al. 1996). This pattern of expression is consistent with the upregulation of Sox9 being a direct effect of SRY action. It also suggests that it is involved in determining Sertoli cell fate. Significantly, $\mathrm{XY}$ human individuals with mutations in one allele of SOX9, frequently show male to female sex reversal (Foster et al. 1994; Wagner et al. 1994). The mutations are found in different regions of the protein implicating several domains, including the HMG box and transcriptional activation domain, in its function in sexual development (Kwok et al. 1996; Meyer et al. 1997). The mutations are also consistent with haploinsufficiency for SOX9 being responsible for the phenotype; that is, the protein has to reach above a criticical threshold to be effective. The close association of Sox 9 expression with Sertoli cell fate and the consequences of mutations in the human gene argue that Sox 9 is essential for early testis development.
Other vertebrates, even if they lack the Sry gene, show conserved expression patterns of Sox 9 in the ovary and testis. Chicken and turtle Sox 9 gene expression is associated with the developing testis but not with the ovary (Kent et al. 1996; Morais da Silva et al. 1996; Spotila et al. 1998). These species have very different sex-determining mechanisms, with chickens having a ZZ/ZW chromosome-based switch and turtles having a temperature-sensitive switch. These studies suggest that Sox9 is important in testis development in many species and that it is the common direct downstream gene of different sex determining mechanisms.

\section{Other main characters}

The studies described above are consistent with the model that one of the main roles of SRY is to upregulate Sox 9 expression in Sertoli cell precursors. The molecular mechanism of SRY action has yet to be determined, but there are a few candidate genes thought to be part of this mechanism. The best described of these is Dax1, an Xlinked member of the nuclear hormone receptor (NHR) superfamily. Studies in the mouse have shown that Dax1 is expressed in the genital ridge at the same time as Sry but in both sexes (Swain et al. 1996). As differentiation proceeds Dax1 is down-regulated in the testis but stays on in the ovary (Fig. 4). Genetic data have provided proof that Dax1 is part of the sex-determination mechanism, but that it is not required for testis formation. In humans, inactivating mutations of DAX1 do not affect $X Y$ male development; however, duplications of the portion of the $\mathrm{X}$ chromosome that includes $D A X 1$ can cause XY female sex reversal (Bardoni et al. 1994; Muscatelli et al. 1994; Zanaria et al. 1994). That DAX1 is the gene responsible for the latter was shown in transgenic mouse experiments, where overexpression of Dax1 alone was 


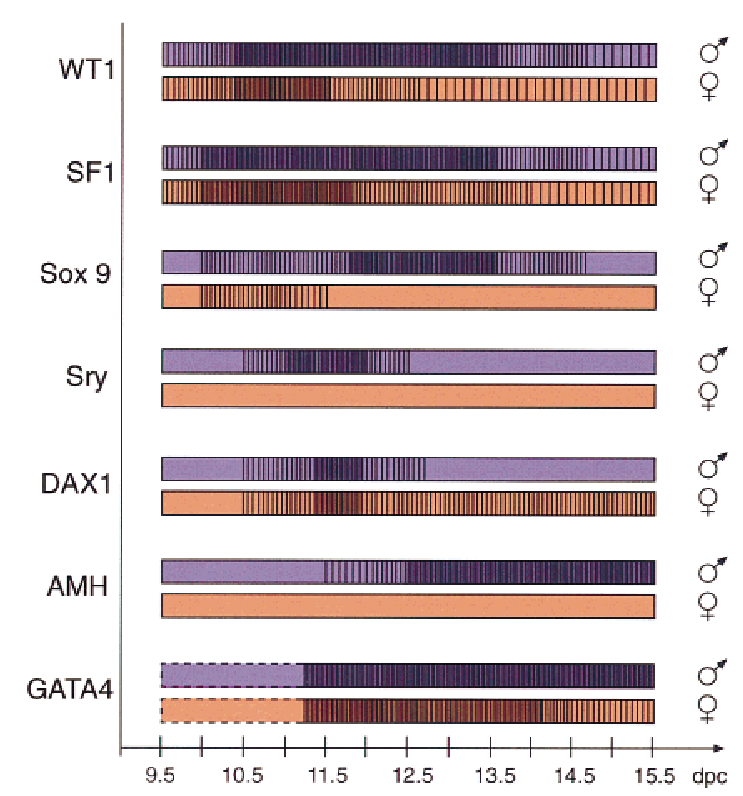

Figure 4. Expression pattern in the gonad during development. Shown are the expression patterns of genes involved in sex determination in the male and female gonad at different stages of embryonic development. The pattern of expression depicted is representative of the gonad as a whole up to $12 \mathrm{dpc}$, which includes precursors to supporting cells (Sertoli cells in the male and follicle cells in the female) and possibly steroidogenic cells (Leydig cells in the male and theca cells in the female). After 12 $\mathrm{dpc}$, the pattern depicted is representative of supporting cells in both sexes. Expression of GATA4 in the early stages of genital ridge development is not known.

able to give $\mathrm{XY}$ female sex reversal in certain genetic backgrounds (Swain et al. 1998). Also, these experiments indicated that DAX1 acts antagonistically to SRY and acts as an antitestis gene.

DAX1 is also thought to act in the same pathway as SF1. Their patterns of expression correlate quite closely and include the gonad, adrenal, hypothalamus, and pituitary, implicating both these genes in reproductive function (Ikeda et al. 1996). All of these tissues are affected in mice deficient for SF1 and in XY humans with mutations of $D A X 1$. The phenotypes though related are not the same indicating a complex interaction between these two genes. The most striking difference between the phenotypes is in the gonad. SF1-deficient mice lack gonads whereas XY individuals and mice deleted for DAX1 show normal testis development.

DAX1 is an unusual member of the nuclear hormone receptor family in that it does not possess a classical zinc finger-containing DNA-binding domain, but three-anda-half copies of a 67-amino acid repeated motif linked to the ligand-binding domain. Studies from different laboratories have shown that DAX1 can inhibit the transcriptional activation of SF1 in vitro (Ito et al. 1997; Lalli et al. 1997; Zazopoulos et al. 1997; Crawford et al. 1998). SF1 is a known activator of genes involved in steroid biosynthesis and in vitro studies have shown that it interacts with a coactivating complex in a similar way to other nuclear hormone receptors (Ito et al. 1998). It has been proposed that the mechanism of repression by DAX1 involves direct protein-protein interaction with SF1, and either direct repression of transcription or recruitment by DAX1 of the nuclear receptor corepressor, N-COR, a known silencer of nuclear hormone receptor mediated transcription. These inhibitory properties have been mapped to the carboxyl terminus of DAX1 and importantly this region is deleted from all naturally occurring deletion mutations in humans (Fig. 2). On the other hand, DAX1 could exert its effect directly through DNA binding. Originally it was proposed that DAX1 might bind similar DNA sequences to other NHRs, implying it might work competitively against factors such as SF1. However, more recently, Zazopoulos et al. (1997) suggested that the novel domain in DAX1 is able to bind hairpin-loop structures in DNA. These are predicted to form when unique sequences are flanked by inverted repeats, and Zazopoulos et al. (1997) indeed noted such sequences close to SF1 binding sites in the regulatory regions of candidate target genes. The binding of DAX1 would somehow interfere with SF1 action, which of course could also be via protein-protein interactions and recruitment of $\mathrm{N}$-COR. Clearly, architectural factors such as SRY could influence the likelihood of hairpinloop structures forming, which immediately suggests a mechanism by which SRY and DAX1 could act antagonistically to control the activity of SF1 on one or more critical target genes involved in sex determination. However, there is no evidence for this at present.

Dax 1 and SF1 are coexpressed in the adrenal and deficiencies in both these genes lead to impaired adrenal development. The phenotypes are different, however, in that Sf1-deficient mice lack adrenals altogether, whereas humans with a deletion of the DAX1 gene show absence of the adult zone of the adrenal cortex. Recent studies have shown that mice with a deletion of the carboxyterminal portion of the ligand-binding domain of DAX1 also show abnormal development of the adrenal in that the fetal zone of the cortex does not regress (Yu et al. 1998). In contrast to humans, however, the adult zone is normal and the mutant animals do not suffer adrenal failure. It is not clear whether in this instance DAX1 and SF1 are acting antagonistically or cooperatively. It is possible that the phenotype seen in the DAX1-deficient patients is due to an excess of SF1 function, which might affect mice differently. Alternatively, adrenal-specific factors could counteract DAX1 repression and allow SF1 action. Detailed analysis of adrenals from mice deficient for Dax1 will address this issue. The action of DAX1 on SF1 could also be affected by the presence of a ligand for both or either of these orphan receptors. The sequence of the SF1 and DAX1 ligand-binding domains suggests they can interact with a ligand and this idea is supported by in vitro studies where deletions of the SF1 ligand binding domain lead to an increase in SF1-mediated transactivation of Amh-reporter constructs (Shen et al. 1994). Attempts to find ligands that may operate in vivo have so far given equivocal results. Oxysterols have been reported to potentiate SF1 activation in CV1 cells, which do not express SF1, but they have no effect in MA-10 
cells, which are of Leydig cell origin and do express SF1 (Lala et al. 1997; Mellon and Bair 1998).

It remains to be established whether SF1 has a critical role in sex determination per se, that is, the decision to be testis rather than ovary, in addition to being generally required for gonadal development. The expression of Sf1 is identical in XX and XY genital ridges up to the stages when Sry is expressed in the male, but subsequently, higher levels of Sf1 are associated with the testis. Some of this is due to the differentiation of Leydig cells, where SF1 is clearly required for steroidogenesis, but Sertoli cells also appear to have higher levels of $S f 1$ than follicle cells (Shen et al. 1994). SF1 could therefore participate in the determination and differentiation of Sertoli cells, first by being an upstream regulator of either Sry or Sox 9 or both, but secondly by being downstream of these. Perhaps SF1 and SOX9 are mutually dependent on each other for their continued expression at a high level. SF1 could then participate in subsequent Sertoli cell-specific gene regulation.

The pattern of expression of SF1 is complementary to that of DAX1 in the gonad and suggests that these receptors act antagonistically to each other, consistent with the in vitro studies. In the early genital ridge, $S f 1$ expression precedes a low level of Sox 9 expression in both sexes. The upregulation of Sox 9 follows immediately the onset of Sry expression, whereas in the XX gonad, the extinction of Sox9 expression is remarkably consistent with the onset of Dax1 expression (Fig. 4). Perhaps the role of DAX1 in females would be to prevent Sox 9 transcription through repression of SF1 action. However, XX mice deleted for Dax1 have normal ovaries and female reproductive tract, suggesting that it cannot be the only repressor of testis-specific genes in the early ovary (Yu et al. 1998). In the male, the role of SRY would be to prevent this repression and perhaps to contribute directly to Sox9 activation. Once SOX9 levels reach a critical threshold, it could help maintain its own expression through an autoregulatory loop. It is clearly important to characterize the regulatory regions of Sox 9 in detail to see if any of this speculation is based in reality.

Other candidate genes involved in sex determination are less characterized. Eicher and colleagues have identified three loci in mice that seem to modulate Sry action (Eicher et al. 1995). These studies employed the Sry gene from the Mus domesticus poschiavinus Y chromosome, which acts as a weak allele $\left(S r y^{p o s}\right)$. This works well enough on most genetic backgrounds, although testis differentiation can be delayed. However, when present on a C57BL/ 6 genetic background, the Sry ${ }^{\text {pos }}$ allele fails to determine testis development, giving rise instead to $\mathrm{XY}$ females or hermaphrodites. The autosomal loci involved in this effect have been mapped to chromosome 4 (tda-1), 2 (tda-2), and 5 (tda-3) (Eicher et al. 1996). It has been proposed that these loci code for factors that promote ovary development, those derived from C57BL/6 being stronger acting. However, recent experiments suggest that the defect in Sry ${ }^{p o s}$ is at the transcriptional level as the amount of transcript present in the genital ridge is lower than that found with other Sry alleles (C.
Nagamine, pers. comm.; A. Swain and R. Lovell-Badge, unpubl.). It is clearly necessary to characterize the autosomal loci to really understand how they fit into the pathway.

\section{Testis development: the drama unfolds}

\section{Sertoli cell differentiation: Amh regulation}

Once Sertoli cell fate is triggered by SRY, genes involved in Sertoli cell function become activated. One of these genes is $A m h$. Its product, $\mathrm{AMH}$, which is a member of the TGF $\beta$ family, induces the regression of the Mullerian ducts, which in the female give rise to the oviducts and uterus. The Amh gene is first expressed at $12 \mathrm{dpc}$ in the developing Sertoli cells of the mouse testis in a pattern that closely follows the upregulation of Sox9 (see Fig. 4) (Munsterberg and Lovell-Badge 1991; Morais de Silva et al. 1996). A number of studies have focused on Amh gene regulation, however, most have relied on in vitro experiments and their conclusions await true in vivo validation. The Amh locus is rather peculiar in that the transcriptional start site is only $\sim 300$ bp downstream of the polyadenylation site of a gene that encodes a spliceosome associated protein SAP62 (Dresser et al. 1995). SAP62 is ubiquitously expressed, whereas Amh expression is tightly regulated. One in vivo study used 180 base pairs upstream of the transcriptional start site of $A m h$ linked to a heterologous marker, which was analysed in transgenic mice (Giuili et al. 1997). One out of the three transgenic lines that were analysed in this study was found to have marker expression restricted to the developing Sertoli cells. Within this Amh promoter region is a consensus binding site for SF1 (Shen et al. 1994). When this binding site was mutated so that SF1 binding was abolished, and introduced into transgenic mice, no marker expression was observed in the embryonic testis (three transgenic lines were analysed). The numbers are low, but these results are consistent with the in vitro data, which shows that SF1 can bind and activate the Amh promoter.

Although SF1 is a good candidate for an activator of Amh gene expression, it cannot account for its tissue specificity. SF1 is expressed in other cells where $A m h$ is not, such as the embryonic Leydig and adrenal cells and in the developing ovary, although in this last case at lower levels. The Amh promoter region also contains a consensus binding site for proteins containing an HMG box domain. In vitro studies have shown that SRY can bind to this sequence but only very weakly (Haqq et al. 1993). Evidence from the developmental expression studies suggest that $A m h$ is not a direct downstream target of SRY as the advent of Amh expression occurs at least $24 \mathrm{hr}$ later than Sry and continues to be expressed throughout Sertoli cell differentiation when Sry transcripts are not present. A better candidate to bind to the HMG box consensus site is SOX9. This is present in the male genital ridge at the time that $A m h$ is activated and continues to be expressed in Sertoli cells throughout development and adulthood. Contrary to SF1, Sox9 is not expressed in the adrenal or Leydig cells and it is turned off in the female genital ridge at $11.5 \mathrm{dpc}$. Consistent 
with this, recent in vitro evidence by de Santa Barbara et al. (1998) and our unpublished observations have indicated that SOX9 will bind to the HMG box consensus site in the Amh gene. Also, SOX9 can synergize SF1 activation of the Amh promoter suggesting that both factors act in concert to bring about tissue specific expression of Amh.

WT1 has also been implicated in the regulation of Amh expression. In vitro studies have shown that WT1 can potentiate the activation of $A m h$ by SF1 (Nachtigal et al. 1998). This property of WT1 was only seen for the -KTS isoform. In this context, WT1 seems to be acting as a coactivator, as it is unable to activate or bind to $\mathrm{Amh}$ reporter constructs on its own. Consistent with this, SF1 and WT1 proteins were found to interact directly, although this complex was not observed on the DNA in a gel shift assay. There is in vivo precedence for the involvement of WT1 in testis development: It is expressed in Sertoli cells of the developing testis and heterozygous Denys-Drash type mutations in humans will give rise to genital abnormalities with a higher frequency in males than in females. Also, these WT1 mutations are often associated with perstistent Mullerian duct structures in humans. The -KTS isoforms of WT1, carrying mutations in the carboxy-terminal zinc finger DNA-binding domain derived from Denys-Drash patients, were found not to synergize SF1 activation in the in vitro assays. This suggests that the DNA-binding domain of WT1 is involved in the function of the protein as a coactivator. However, the domain that interacts with SF1 was mapped to the amino terminus. Contrary to what was expected from the dominant phenotype seen in DenysDrash patients, the coactivating properties of wild-type WT1 were not affected by the presence of the mutant forms of WT1. This suggests that the situation in these patients involves more that one mechanism of action by WT1. Further in vivo studies are needed to dissect the role of WT1 in Amh regulation and testis development and give insight into the cause of the diseases where this gene is involved.

The role of DAX1 in early testis development and Amh regulation is unclear. The transgenic experiments showed that DAX1 can be antagonistic to SRY action when expressed at high levels, but what is its normal role in testis development? DAX1 has been shown in vitro to function as a repressor in the context of SF1 mediated activation, with several studies suggesting that this occurs via protein-protein interaction (Ito et al. 1997; Crawford et al. 1998). Also, DAX1 has recently been shown to repress the synergistic action of SF1 and WT1 on the Amh promoter in vitro (Nachtigal et al. 1998). This suggests that it plays an inhibitory role in testis development and that significant levels of DAX1 should not be present in Sertoli cells if they are to produce AMH. However, the results on this are inconsistent. Whole mount in situ hybridization showed that Dax1 expression is down-regulated in the developing testis at $12.5 \mathrm{dpc}$ while it continued to be expressed in the ovary (Swain et al. 1996). In agreement with this, porcine Dax1 is associated predominantly with the developing ovary, not the testis (Pilon et al. 1998). Also, in a different set of experiments, when a region of the Dax1 gene was used to drive lac $Z$ expression in mice, the gonadal expression was found to be consistent with that of the whole mount studies. LacZ activity was highest at 11.5 $\mathrm{dpc}$ in males and females and then was down-regulated in the male at $12.5 \mathrm{dpc}$, while it remained on in the female (Swain et al. 1998). However, when radioactive in situ hybridization was used on sections of mouse gonads, which is probably a more sensitive technique, Dax1 transcripts were detected in the developing testis in a manner similar to that of SF1 (Ikeda et al. 1996). Further studies using other techniques, such as immunocytochemistry with a DAX1 antibody, are necessary to resolve this inconsistency. The normal role for DAX1 in the ovary may be to prevent expression of genes such as $A m h$. This would make sense, in that Dax1 expression is clearly maintained in the ovary at a time when $A m h$ is expressed in the testis. However, recent results from gene targeting of Dax1 in mice suggest that DAX1 is not critical to repress $A m h$ expression, as homozygous mutant females had normal Mullerian duct derivatives and were fertile (Yu et al. 1998). Therefore, even if DAX1 is involved, it can not be the only repressor.

The AMH promoter element also contains a consensus binding site for the GATA family of transcription factors. Three members of the family are found in the testis and ovary, GATA1, GATA4, and GATA6, but of these, GATA4 is the only one present in the developing gonads (Viger et al. 1998). At $11.5 \mathrm{dpc}$ it is in the genital ridge of both sexes and it is found later in the Sertoli and interstitial cells of the developing testis and also in the developing ovary. GATA4 protein binds to the consensus site in the $A m h$ promoter and activates expression of a reporter construct in vitro. The GATA4 expression pattern in the gonad, however, suggests that it might act at several levels in gonad development, furthermore, it alone can not be responsible for $A m h$ regulation. High levels of GATA4 are present in the ovary up until $16 \mathrm{dpc}$. Also, GATA consensus binding sites are found in upstream regions flanking both the $S f 1$ and $W t 1$ genes. Mice deficient for GATA4 die in utero between 8.5 and $10.5 \mathrm{dpc}$, before gonad development takes place (Molkentin et al. 1997). Conditional mutations in GATA4 will be necessary to determine the role for this factor in gonad development in vivo.

The interpretations of the data from the in vitro studies described above on WT1, GATA4, and SOX9 are tantalizing but carry the obvious caveats of these types of studies. For example, the cell types used were not derived from embryonic gonads, the factors analysed were tested in isolation or together with SF1 only, and the role of a putative ligand for SF1 could not be assessed. Therefore it is dangerous to make hard conclusions based on these studies, but they do indicate directions that the in vivo studies should take to further our understanding.

\section{Germ cell differentiation}

After colonizing the genital ridge, the germ cells follow 
two different developmental pathways depending on the sex of the gonad they are in. In the early differentiating testis they go into mitotic arrest whereas in the early ovary they go into meiotic arrest. When germ cells differentiate in ectopic tissues, such as the adrenal, where they sometimes migrate by mistake, they will go into meiotic arrest (McLaren 1995). This suggests that these cells are programmed to arrest in meiosis and that the role of the embryonic testis is to produce a factor that will make them go into mitotic arrest and therefore trigger a spermatogenic fate. The molecular nature of this factor is not known, but it is probably produced by the Sertoli cells.

A central role of Sertoli cells is to sustain germ cells during development and later during spermatogenesis. They do so by forming close cell-cell contacts and providing factors involved in growth and differentiation. A candidate factor involved in cell-cell interactions between Sertoli and germ cells is Desert hedgehog (Dhh), a member of the hedgehog family of molecules that signal at close range. Expression studies have shown that it is present in male, but not female, gonads at $11.5 \mathrm{dpc}$ and at later stages of testis development it is associated with Sertoli cells (Bitgood et al. 1996). The early expression pattern suggests that Dhh is a direct target of SOX9 or SRY although this has not been studied in any detail.

Male mice deficient for Dhh are infertile owing to absence of sperm. Analysis of the mutant mice showed that testis weights were reduced compared to wild-type mice from early embryonic stages. In later stages, histological analysis showed a germ cell deficiency and block in spermatogenesis that varied with the genetic background. However, the role of Dhh in the early testis has not been fully investigated. It is unclear as to whether the reduction in size is due to a block in proliferation of germ cells or Sertoli cells or both. It is also possible that, in the testis, $\mathrm{DHH}$ could contribute to the signal that makes germ cells enter into mitotic arrest, whereas in its absence, cells go into meiotic arrest. Meiotic germ cells are known to degenerate when in a testis, which is due at least in part to the action of AMH. If this is the case, the number of germ cells present in the Dhh-mutant testes would be reduced and this effect would account for some of the reduction of size in the embryological testis. This could be tested by looking for germ cells in meiotic arrest in the testis of mice that are deficient for both $D h h$ and Amh. Curiously, the putative receptor for the hedgehog family of proteins, patched, is expressed in interstitial cells of the developing testis and not germ cells, which implies that DHH acts indirectly on germ cells.

\section{Cord formation}

Once the Sertoli cells become determined they are thought to direct the differentiation of the rest of the testis. Very little is known about molecular candidates involved in this process. Analysis of mouse chimeras derived from XX and XY cells has shown that when $25 \%$ or more gonadal cells are XY, a testis develops (Palmer and Burgoyne 1991). The Sertoli cells in the chimeric testis are mostly derived from the XY cells but a few XX Sertoli cells are also found. Sry is thought to determine Sertoli cells in a cell-autonomous manner, therefore Sertoli cells must then recruit XX cells to their fate through non-cell-autonomous products. The rest of the cell types in these chimeric testes have no chromosomal bias suggesting that Sertoli cells direct the differentiation of these cell lineages through cell-cell interactions and/or secreted products. Candidates for these interaction factors are members of the wnt family of cell signaling molecules.

A recent report by Vainio et al. (1999) has indicated that Wnt4 is part of the signal involved in controlling steroid production in the early gonad. Leydig cells, which are the steroidogenic cells of the testis, start producing testosterone once the testicular cords have been formed, at $\sim 12.5-13 \mathrm{dpc}$ in the mouse. In the ovary, the theca cells are not active until birth. XX mice that lack Wnt4 show activation of genes that code for enzymes involved in testosterone biosynthesis in the early ovary and masculinization of the Wolffian duct. Wnt4 is expressed initially in the genital ridge and mesonephros but as gonad development proceeds it is downregulated in the testis but remains in the ovary. This suggests that Leydig cell precursors are present in the early genital ridge and that testosterone production in these cells is repressed by the presence of Wnt4. Sry then acts in the male, presumably through the determination of Sertoli cell fate, to downregulate Wnt4 expression and steroidogenesis is allowed to proceed. The details of this model, such as which cell types express Wnt4 and which cells respond to its signal, need to be corroborated but these experiments have opened up a whole new area of study in early gonad development.

Of the events downstream of Sertoli cell differentiation, the formation of testicular cords in the developing testis has been the only process studied in any detail. Organ culture experiments have shown that the mesonephros is essential for testis cord formation (Buehr et al. 1993; Merchant-Larios et al. 1993). In elegant studies using mesonephroi derived from mice carrying an ubiquitously expressed lacZ gene, it was shown that cells from the mesonephros migrate into the developing gonad and give rise to endothelial and peritubular myoid cells in the testis (Martineau et al. 1997). This type of migration only occurred when the cultured gonad was derived from an XY embryo. This suggests that the Sertoli cells of the early testis produce a signal that triggers the movement of cells from the mesonephros to the gonad so that testis cords can be formed. The molecular identity of this signal is not known but it seems to act over considerable distances and behave as a chemoattractant.

\section{New characters}

A recent addition to the growing list of candidate players in the field of mammalian sexual development was identified as a relative of a family of genes involved in both $C$. elegans and Drosophila sex determination (Raymond et al. 1998). Sex-determining mechanisms are very different 
throughout the animal kingdom and a conserved family of genes was an unexpected finding. This family is related through their DNA-binding domain, termed the DM domain, which chelates zinc and confers sequencespecific DNA binding but is distinct from a classical zinc finger domain. The mab3 gene in C. elegans and the $d s x$ gene in Drosophila are not only related in their sequence but also in their function. Both these genes control the differentiation of sex specific structures and act downstream of the global regulators, tra1 in C. elegans and sex lethal in Drosophila, of the sex-determination heirarchy. Database searches for genes related to mab3 identified a human gene, named DMT1, which contained a similar DM domain. Interestingly, DMT1 mapped to a locus involved in human sex reversal on the distal short arm of chromosome 9. XY individuals with deletions or unbalanced translocations, that make them monosomic for distal $9 \mathrm{p}$, display male-to-female sex reversal. It is too early in the characterization of DMT1 to speculate whether it is involved in sex determination or early testis development. It cannot play exactly the same role as it does in the two invertebrate species where it regulates aspects of yolk protein expression and peripheral nervous system development. Nevertheless it is an exciting new candidate to investigate.

\section{Denouement}

A molecular picture is beginning to emerge for mammalian sex determination, at least with respect to the known transcription factors. These can be classified into at least three groups. The first are general transcription factors, which are likely to be involved at several different stages, if not continuously, from early genital ridge development through to differentiation of specific cell types in the gonads. These will include factors such as LIM1, SF1, WT1, and GATA4. The second group, represented by SRY and SOX9, are specific promoters of testis development. Members of the third group work against testis development and may promote ovary development. The only representative of this class we know of so far is DAX1, but there are likely to be several others given the significant number of cases of $S R Y$-negative XX males.

The picture is confusing because of the extent of the interactions between the genes. For members of the first group, although they are expressed in much broader domains than the genital ridge, it is the unique combination of factors that is critical, and which must specify the various cell types, such as the supporting and steroidogenic cell lineages. These factors are not really sex specific but could be more significant in one sex than in the other. For example, they may be involved in particular cellular processes, such as epithelial-mesenchyme transitions, which are more critical for testis morphogenesis. Furthermore, at least several factors among this first group are likely to be positive regulators of the genes that have a more focused role in the sex determination switch, that is, of Sry, Sox9, and Dax1. Finally, the products of the switch may well act on their own targets in conjunction with representatives of the first group. For example, Amh regulation may depend on SOX9 for Sertoli cell-specific expression, but it can not do this alone and requires the participation of SF1 and perhaps GATA4 and WT1. As SOX9 is also expressed in many other sites within the embryo, this unique combination is needed for Sertoli cell specific expression. Also, levels of expression are an important part of this molecular picture. The switch genes, Sry, Sox9, and Dax1, all show dosage or threshold effects, but this is less important for the general transcription factors, where heterozygosity for null mutations has little or no effect.

Once Sertoli cell differentiation is triggered, there must be regulatory loops to maintain this state. These could be autoregulatory, such as SOX9 acting on its own promoter, but there is good evidence that cell-cell communication is important. So some critical sex-specific targets of the transcription factors are likely to be signaling molecules, conveying the decision occurring within the supporting cell lineage to the other gonadal cell types. These then return a reinforcing signal. AMH, $\mathrm{DHH}$, and WNT4 are some of these signals.

So how much of the play remains to be discovered? The parts of the story that are most understood are those concerning the supporting cell lineage and even then this is biased toward the male, Sertoli cell pathway. It still seems very likely that there will be critical genes involved in establishing follicle cell fate. However, it is less clear how cell autonomous this process is. It is hard to distinguish somatic cells of the early ovary from those of the indifferent gonad at $11.5 \mathrm{dpc}$. Although there are some molecular changes, these mostly involve a change in levels of gene expression. Proper follicular organization depends on the presence of oocytes and in their absence there is often 'transdifferentiation' toward testicular tissue, including XX Sertoli cells (for examples of this sex reversal, see Morais da Silva et al. 1996; Vainio et al. 1999).

Many aspects of the early embryology and cell biology of the gonads need to be worked out. For example, what determines the position and timing of genital ridge development? What is the relationship, if any, between the suppporting and steroidogenic cell lineages, that is, do they come from a common precursor, perhaps in the coelomic epithelium, or from two different sources? How important is the migration of cells from the mesonephros into the developing testis after $11.5 \mathrm{dpc}$ ? Is this a critical step without which the Sertoli cell phenotype would be lost? If so, one might expect to find cases of sex reversal due to mutations of genes involved in this migration, or in the communication between the peritubular myoid cells and the Sertoli cells. Similarly, although they are perhaps irrelevant to sex determination, germ cells are of course the raison d'etre for gonads and whether the germ cells become sperm or oocytes depends on signals from the somatic cells. These signals remain a mystery. Finally, the various cell types making up an ovary or a testis have to be organized to make a functional structure. This becomes more elaborate later on, but the structures are relatively simple at early 
stages. Gonadal development therefore provides an excellent model to study organogenesis and its genetic control.

\section{Acknowledgments}

We are grateful to members of our laboratories for helping us keep the story straight and hopefully away from farce or tragedy. We acknowledge the MRC and Louis Jeantet Foundation for financial support. A.S. is a recipient of an MRC Career Development Award.

\section{References}

Barbaux, S.P., M.C. Niaudet, J.P. Gubler, F. Grunfeld, F. Jaubert, C.N. Kuttenn, N. Fekete, E. Souleyreau-Therville, M. Thibaud, M. Fellous, and K. McElreavey. 1997. Donor splicesite mutations in WT1 are responsible for Frasier syndrome. Nat. Genet. 17: 467-470.

Bardoni, B., E. Zanaria, S. Guioli, G. Floridia, K.C. Worley, G. Tonini, E. Ferrante, G. Chiumello, E.R. McCabe, M. Fraccaro, et al. 1994. A dosage sensitive locus at chromosome $\mathrm{Xp} 21$ is involved in male to female sex reversal. Nat. Genet. 7: 497-501.

Bel, S., N. Core, M. Djabali, K. Kieboom, N. Van der Lugt, M.J. Alkema, and M. Van Lohuizen. 1998. Genetic interactions and dosage effects of Poycomb group genes in mice. Development 125: 3543-3551.

Bitgood, M.J., L.Shen, and A.P. McMahon. 1996. Sertoli cell signalling by Desert hedgehog regulates the male germline. Curr. Biol. 6: 298-304.

Buehr, M., S. Gu, and A. McLaren. 1993. Mesonephric contribution to testis differentiation in the fetal mouse. Development 117: 273-281.

Core, N., S. Bel, S.J. Gaunt, M. Aurrand-Lions, J. Pearce, A. Fisher, and M. Djabali. 1997. Altered cellular proliferation and mesoderm patterning in Polycomb-M33-deficient mice. Development 124: 721-729.

Crawford, P.A., C. Dorn, Y. Sadovsky, and J. Milbrandt. 1998. Nuclear receptor DAX-1 recruits nuclar receptor corepressor N-CoR to Steroidogenic Factor 1. Mol Cell Biol. 18: 2949_ 2956.

De Santa Barbara, P.N. Bonneaud, B. Boizet, M. Desclozeaux, B. Moniot, P. Sudbeck, G. Scherer, F. Poulat, and P. Berta. 1998. Direct interaction of SRY-related protein SOX9 and Sterodogenic Factor 1 regulates transcription of the human AntiMullerian hormone gene. Mol. Cell. Biol. 18: 6653-6665.

Dolle, J-C., Izpisua-Belmonte, J.M. Brown, C. Tickle, and D. Duboule. 1991. Hox-4 genes and the morphogenesis of mammalian genitalia. Genes \& Dev. 5: 1767-1776.

Dresser, D.W., A. Hacker, R. Lovell-Badge, and D. Guerrier. 1995. The genes for a spliceosome protein (SAP62) and the anti-Mullerian hormone (AMH) are contiguous. Hum. Mol. Genet. 4: 1613-1618.

Eicher, E.M., E.P. Shown, and L.L. Washburn. 1995. Sex reversal in C57BL/6J-YPOS mice corrected by a Sry transgene. Philos. Trans. R. Soc. Lond. B. Biol. Sci. 350: 263-268.

Eicher, E.M., L.L. Washburn, N.J. Schork, B.K. Lee, E.P. Shown, X. Xu, R.D. Dredge, M.J. Pringle, and D.C. Page. 1996. Sexdetermining genes on mouse autosomes identified by linkage analysis of C57BL/6- YPOS sex reversal. Nat. Genet. 14: 206-209.

Foster, J.W, M.A. Dominguez-Steglich, S. Guioli, G. Kowk, P.A. Weller, M. Stevanovic, J. Weissenbach, S. Mansour, I.D.
Young, P.N. Goodfellow et al. 1994. Campomelic dysplasia and autosomal sex reversal caused by mutations in an $S R Y$ related gene. Nature 372: 525-530.

Fujii, T., J.G. Pichel, M. Taira, R. Toyama, I.B. Dawid, and H. Wetphal. 1994. Expression patterns of the murine LIM class homeobox gene lim1 in the developing brain and excretory system. Dev. Dyn. 199: 73-83.

Ginsburg, M., M. Snow, and A. McLaren. 1990. Primordial germ cells in the mouse embryo during gastrulation. Development 110: $521-528$.

Giuili, G., W.H. Shen, and H.A. Ingraham. 1997. The nuclear receptor SF-1 mediates sexually dimorphic expression of Mullerian Inhibiting Substance in vivo. Development 124: 1799-1807.

Gubbay, J., J. Collignon, P. Koopman, B. Capel, A. Economou, A. Munsterberg, N. Vivian, P.N. Goodfellow, and R. LovellBadge. 1990. A gene mapping to the sex determining region of the mouse Y chromosome is a member of a novel family of embryonically expressed genes. Nature 346: 245-250.

Gubbay, J., N. Vivian, A. Economou, D. Jackson, P. Goodfellow, and R. Lovell-Badge. 1992. Inverted repeat structure of the Sry locus in mice. Proc. Natl. Acad. Sci. 89: 7953-7957.

Hacker, A., B. Capel, P. Goodfellow, and R. Lovell-Badge. 1995. Expression of Sry, the mouse sex determining gene. Development 121: 1603-1614.

Haqq, C.M., C.-Y. King, E. Ukiyama, S. Falsafi, T.N. Haqq, P.K. Donahoe, and M.A. Weiss. 1994. Molecular basis of mammalian sexual determination: Activation of mullerian inhibiting substance gene expression by SRY. Science 266: 14941500 .

Harley, V.R., D.I. Jackson, P.J. Hextall, J.R. Hawkins, G.D. Berkovitz, S. Sockanathan, R. Lovell-Badge, and P.N. Goodfellow. 1992. DNA binding activity of recombinant SRY from normal males and XY females. Science 255: 453-456.

Hawkins, J.R., A. Taylor, P.N. Goodfellow, C.J. Migeon, K.D. Smith, and G.D. Berkovitz. 1992. Evidence for increased prevalence of SRY mutations in XY females with complete rather than partial gonadal dysgenesis. Am. J. Hum. Genet. 51: 979-984.

Hatano, H., A. Takakusus, M. Nomura, and K. Morohashi. 1996. Identical origin of adrenal cortex and gonad revealed by expression profiles of Ad4BP/SF1. Genes Cells 1: 663-671.

Hatano, O., K. Takayama, T. Imai, M.R. Waterman, A. Takakusu, T. Omura, and K. Morohashi. 1994. Sex-dependent expression of a transcription factor, Ad4BP, regulating steroidogenic P-450 genes in the gonads during prenatal and postnatal rat development. Development 120: 2787-2797.

Honda, S., K. Morohashi, M. Nomura, H. Takeya, M. Kitajima, and T. Omura. 1993. Ad4BP regulating steroidogenic P-450 gene is a member of steroid hormone receptor superfamily. J. Biol. Chem. 268: 7494-7502.

Ingraham, H.A., D.S. Lala, Y. Ikeda, X. Luo, W.H. Shen, M.W. Nachtigal, R. Abbud, J.H. Nilson, and K.L. Parker. 1994. The nuclear receptor steroidogenic factor 1 acts at multiple levels of the reproductive axis. Genes \& Dev. 8: 2302-2312.

Ikeda, Y., D.S. Lala, X. Luo, E. Kim, M.P. Moisan, and K.L. Parker. 1993. Characterization of the mouse FTZ-F1 gene, which encodes a key regulator of steroid hybroxylase gene expression. Mol. Endocrinol. 7: 852-860.

Ikeda, Y.W., H.A. Shen, H.A. Ingraham, and K.L. Parker. 1994. Developmental expression of mouse steroidogenic factor 1 an essential regulator of the steroid hydroxylases. Mol. Endocrinol. 8: 654-662.

Ikeda,Y., X. Luo, R. Abbud, J.H. Nilson, and K.L. Parker. 1995. The nuclear receptor steroidogenic factor 1 is essential for the formation of the ventromedial hypothalamic nucleus. 
Mol. Endocrinol. 9: 478-486.

Ikeda, Y., A. Swain, T.J. Weber, K.E. Hentges, E. Zanaria, E. Lalli, K.T. Tamai, P. Sassone-Corsi, R. Lovell-Badge, G. Camerino, and K.L. Parker. 1996. Steroidogenic Factor 1 and Dax-1 co-localize in multiple cell lineages: Potential links in endocrine development. Mol. Endocrinol. 10: 1261-1272.

Ito, M., R.N. Yu, and J.L. Jameson. 1997. DAX-1 inhibits SF-1 mediated transactivation via a carboxy-terminal domain that is deleted in adrenal hypoplasia congenita. Mol. Cell. Biol. 17: 1476-1483.

- 1998. Steroidogenic factor-1 contains a carboxy-terminal transcriptional activation domain that interacts with steroid receptor coactivator-1. Mol. Endocrinol. 12: 290-301.

Jeske, Y.W., J. Bowles, A. Greeenfield, and P. Koopman. 1995. Expression of a linear Sry transcript in the mouse genital ridge. Nat. Genet. 10: 480-482.

Karl, J. and B. Capel. 1998. Sertoli cells of the mouse testis originate from the coelomic epithelium. Dev. Biol. 203: 323333.

Kathoh-Fukui, Y., R. Tsuchiya, T. Shiroishi, Y. Nakahara, N. Hashimoto, K. Noguchi, and T. Higashinakagawa. 1998. Male-to-female sex reversal in M33 mutant mice. Nature 393: 688-692.

Kent, J., S.C. Wheatley, J.E. Andrews, A.H. Sinclair, and P. Koopman. 1996. A male-specific role for Sox9 in vertebrate sex determination. Development 122: 2813-2822.

Koopman, P., J. Gubbay, N. Vivian, P. Goodfellow, and R. Lovell-Badge. 1991. Male development of chromosomally female mice transgenic for Sry. Nature 351: 117-121.

Kreidberg, J.A., H. Sariola, J.M. Loring, M. Maeda, J. Pelletier, D. Housman, and R. Jaenisch. 1993. WT-1 is required for early kidney development. Cell 74: 679-691.

Kwok, C., P.A. Weller, S. Guioli, J.W. Foster, S. Mansour, O. Zuffardi, H.H. Punnett, M.A. Dominguez-Steglich, J.D. Brook, I.D. Young et al. 1995. Mutations in SOX9, the gene responsible for campomelic dysplasia and autosomal sex reversal. Am. J. Hum. Genet. 57: 1028-1036.

Lala, D.S., D.A. Rice, and K.L. Parker. 1992. Steroidogenic factorl, a key regulator of steroidogenic enzyme expression, is the mouse homolog of fushi tarazu factor 1. Mol Endocrinol. 6: $1249-1258$.

Lala, D.S., P.M. Syka, S.B. Lazarchik, D.J. Mangelsdorf, K.L. Parker, and R.A. Heyman. 1997. Activation of the orphan nuclear receptor steroidogenic factor 1 by oxysteros. Proc. Natl. Acad. Sci. 94: 4895-4900.

Lalli, E., B. Bardoni, E. Zapopoulos, J-M. Wurtz, T.M. Strom, D. Moras, and P. Sassone-Corsi. 1997. A transcriptional silencing domain in DAX-1 whose mutation causes Adrenal Hypoplasia Congenita. Mol. Endocrinol. 11: 1950-1960.

Larsson, S.H., J-P. Charlieu, K. Miyagawa, K. Engelkamp, Rassoulzadegan, A. Ross, F. Cuzin, V. van Heyningen, and N.D. Hastie. 1995. Subnuclear localization of WT1 in splicing and transcription factor domains is regulated by alternative splicing. Cell 81: 391-401.

Luo, X., Y. Ikeda, and K.L. Parker. 1994. A cell-specific nuclear receptor is essential for adrenal and gonadal development and sexual differentiation. Cell 77: 481-490.

Martineau, J.J., K. Nordqvist, C. Tilmann, R. Lovell-Badge, and B. Capel. 1997. Male-specific cell migration into the developing gonad. Curr. Biol. 7: 958-968.

McLaren, A. 1995. Germ cells and germ cell sex. Philos. Trans. R. Soc. Lond. B. Biol. Sci. 350: 229-233.

Mellon, S.H. and S.R. Bair. 1998. 25-Hydroxycholesterol is not a ligand for the orphan nuclear receptor steroidogenic factor-1 (SF-1). Endocrinology 139: 3026-3029.

Merchant-Larios, H., N. Moreno-Mendoza, and M. Buehr. 1993.
The role of the mesonephros in cell differentiation and morphogenesis of the mouse fetal testis. Int. J. Dev. Biol. 37: 407-415.

Meyer, J., P. Sudbeck, M. Held, T.Wagner, M.L. Schmitz, F.D. Bricarelli, E. Eggermont, U. Friedrich, O.A. Haas, A. Kobelt, et al. 1997. Mutational analysis of the SOX9 gene in campomelic dysplasia and autosomal sex reversal: Lack of genotype/phenotype correlations. Hum. Mol. Genet. 6: 91-98.

Miyamoto, N., M. Yoshida, S. Kuratani, I. Matsuo, and S. Aizawa. 1997. Defects of urogenital development in mice lacking Emx2. Development 124: 1653-1664.

Molkentin, J.D., Q. Lin, S.A. Duncan, and E.N. Olson. 1997. Requirement of the transcription factor GATA4 for heart tube formation and ventral morphogenesis. Genes \& Dev. 11: 1061-1072.

Morais da Silva, S., A. Hacker, V. Harley, P. Goodfellow, A. Swain, and R. Lovell-Badge. 1996. Sox9 expression during gonadal development implies a conserved role for the gene in testis differentiation in mammals and birds. Nat. Genet. 14: 62-68.

Morohashi, K., S. Honda, Y. Inomata, H. Handa, and T. Omura. 1992. A common trans-acting factor, Ad4-binding protein, to the promoters of steroidogenic P-450s. J. Biol. Chem. 267: 17913-17919.

Morohashi, K., U.M. Zanger, S. Honda, M. Hara, M.R. Waterman, and T. Omura. 1993. Activation of CYP11A and CYP11B gene promoters by the steroidogenic cell-specific transcription factor, Ad4BP. Mol. Endocrinol. 7: 1196-1204.

Morohashi, K., H. Iida, M. Nomura, O. Hatano, S. Honda, T. Tsukiyama, O. Niwa, T. Hara, A. Takakusu, Y. Shibat et al. 1994. Functional difference between Ad4BP and ELP, and their disributions in teroidogenic tissues. Mol. Endocrinol. 8: 643-653.

Morohashi, K. The ontogenesis of the steroidogenic tissues. 1997. Genes Cells 2: 95-106.

Munsterberg, A. and R. Lovell-Badge. 1991. Expression of the mouse anti-Mullerian hormone gene suggests a role in both male and female sexual differentiation. Development 113: 613-624.

Muscatelli, F. T.M. Strom, A.P. Walker, E. Zanaria, D. Recan, A. Meindl, B. Bardoni, S. Guioli, G. Zehetner, W. Rabl et al. 1994. Mutations in the $D A X-1$ gene give rise to both $\mathrm{X}$ linked adrenal hypoplasia congenita and hypogonadotropic hypogonadism. Nature 372: 672-676.

Nachtigal, M.W., Y. Hirokawa, D.L. Enyeart-VanHouten, J.N. Flanagan, G.D. Hammer, and H.A. Ingraham. 1998. Wilms' tumor 1 and Dax-1 modulate the orphan nuclear receptor SF-1 in sex-specific gene expression. Cell 93: 445-454.

Palmer, S. and P.S. Burgoyne. 1991. In situ analysis of fetal, prepuberal and adult XX-XY chimaeric mouse testes: Sertoli cells are predominantly, but not exclusively, XY. Development 112: 265-268.

Parker, K.L. 1998. The roles of steroidogenic factor 1 in endocrine development and function. Mol. Cell. Endocrinol. 140: 59-63.

Pelletier, J., M. Schalling, A.J. Buckler, A. Rogers, D.A. Haber, and D. Housman. 1991. Expression of the Wilms' tumor gene WT1 in the murine urogenital system.. Genes \& Dev. 5: 1345-1356.

Pilon, N., R. Behdjani, I. Daneau, J.G. Lussier, and D.W. Silversides. 1998. Porcine steroidogenic factor-1 gene (pSF-1) expression and analysis of embryonic pig gonads during sexual differentiation. Endocrinology 139: 3803-3812.

Pontiggia, A., R. Rimini, V.R. Harley, P.N. Goodfellow, R. Lovell-Badge, and M.E. Bianchi. 1994. Sex-reversing mutations affect the architecture of SRY-DNA complexes. EMBO $I$. 
13: 6115-6124.

Pritchard-Jones, E., S. Fleming, D. Davidson, W. Bickmore, D. Porteouse, C. Gosden, J. Bard, A. Buckler, J. Pelletier, D. Housman, V. van Heyningen, and N. Hastie. 1990. The candidate Wilms' tumor gene is involved in genitourinary development. Nature 346: 194-197.

Raymond, C.S., C.E. Shamu, M.M. Shen, K.J. Seifert, B. Hirsch, J. Hodgkin, and D. Zarkower. 1998. Evidence for evolutionary conservation of sex-determining genes. Nature 391: 691695.

Reddy, J.C. and J.D. Licht. 1996. The WT1 Wilms' tumor suppressor gene: How much do we really know? Biochim. Biophys. Acta 1287: 1-28.

Sadovsky, Y., P.A. Crawford, K.G. Woodson, J.A. Polish, M.A. Clements, L.M. Tourtellotte, K. Simburger, and J. Milbrandt. 1995. Mice deficient in the orphan receptor steroidogenic factor 1 lack adrenal glands and gonads but express P450 side-chain-cleavage enzyme in the placenta and have normal embryonic serum levels of corticosteroids. Proc. Natl. Acad. Sci. 92: 10939-10943.

Sainio, K., P. Hellstedt, J.A. Kreidberg, L. Saxen, and H. Sariola. 1997. Differential regulation of two sets of mesonephric tubules by WT-1. Development 124: 1293-1299.

Sinclair, A.H., P. Berta, M.S. Palmer, J.R. Hawkins, B.L. Griffiths, M.J. Smith, J.W. Foster, A.M. Frischauf, R. LovellBadge, and P.N. Goodfellow. 1990. A gene from the human sex-determining region encodes a protein with homology to a conserved DNA-binding motif. Nature 346: 240-244.

Sharma, P.M., M. Bowman, S. Madden, F.J. Rauscher III, and S. Sukumar. 1994. RNA editing in the Wilms' tumor susceptibility gene, WT1. Genes \& Dev. 8: 720-731.

Shawlot, W. and R.R. Behringer. 1995. Requirement for Lim1 in head-organizer function. Nature 374: 425-430.

Shen, W.H., C.C. Moore, Y. Ikeda, K.L. Parker, and H.A. Ingraham. 1994. Nuclear receptor steroidogenic factor 1 regulates the mullerian inhibiting substance gene: A link to the sex determination cascade. Cell 77: 651-661.

Shinoda, K., H. Lei, H. Yoshii, M. Nomura, M. Nagano, H. Shiba, H. Sasaki, Y. Osawa, Y. Ninomiya, O. Niwa et al. 1995. Developmental defects of the ventromedial hypothalamic nucleus and pituitary gonadotroph in the Ftz-F1 disrupted mice. Dev. Dyn. 204: 22-29.

Spotila, L.D., J.R. Spotila, and S.E. 1998. Hall Sequence and expression analysis of WT1 and Sox 9 in the red-eared slider turtle, Trachemys scripta. J. Exper. Zool. 281: 417-427.

Swain, A., E. Zanaria, A. Hacker, R. Lovell-Badge, and G. Camerino. 1996. Mouse Dax-1 expression is consistent with a role in sex determination as well as in adrenal and hypothalamus function. Nat. Genet. 12: 404-409.

Swain, A., V. Narvaez, P. Burgoyne, G. Camerino, and R. LovellBadge. 1998. Dax1 antagonizes Sry action in mammalian sex determination. Nature 391: 761-767.

Sudbeck, P., M.L. Schmitz, P.A. Baeuerle, and G. Scherer. 1996. Sex reversal by loss of the C-terminal transactivation domain of human SOX9. Nat. Genet. 13: 230-232.

Torres, M., E. Gomez-Pardo, G.R. Dressler, and P. Gruss. 1995. Pax-2 controls multiple steps of urogenital development. Development 121: 4057-4065.

Tucker, P.K. and B.L. Lundrigan. 1993. Rapid evolution of the sex determining locus in Old World mice and rats. Nature 364: 715-717.

Vainio, S. and U. Muller. 1997. Inductive tissue interactions, cell signaling, and the control of kidney organogenesis. Cell 90: 975-978.

Vainio, S., M. Heikkila, A. Kispert, C. Norman, and A.P. McMahon. 1999. Female development in mammals is regulated by Wnt-4 signalling. Nature 397: 405-500.

Viger, R.S., C. Mertineit, J.M. Trasler, and M. Nemer. 1998. Transcription factor GATA- 4 is expressed in a sexually dimorphic pattern during mouse gonadal development and is a potent activator of the Mullerian inhibiting substance promoter. Development 125: 2665-2675.

Wagner, T., J. Wirth, J. Meyer, B. Zabel, M. Held, J. Zimmer, J. Pasantes, F.D. Bricarelli, J. Keutel, E. Hustert et al. 1994. Autosomal sex reversal campomelic dysplasia are caused by mutations in and around the SRY-related gene SOX 9. Cell 79: $1111-1120$.

Whitfield, S., R. Lovell-Badge, and P.N. Goodfellow. 1993. Rapid sequence evolution of the sex determining gene SRY. Nature 364: 713-715.

Yu, R.N., M. Ito, T.L. Saunders, S.A. Camper, and J.L. Jameson. 1998. Role of Ahch in gonadal development and gametogenesis. Nat. Genet. 20: 353-357.

Zanaria, E., B. Bardoni, B. Dabovic, V. Calvari, M. Fraccaro, O. Zuffardi, and G. Camerino. 1994. An unusual member of the nuclear hormone receptor superfamily responsible for X-linked adrenal hypoplasia congenita. Nature 372: 635641.

Zazopoulos, E., E. Lalli, D.M. Stocco, and P. Sassone-Corsi. 1997. DNA binding and transcriptional repression by DAX-1 blocks steroidogenesis. Nature 390: 311-315. 


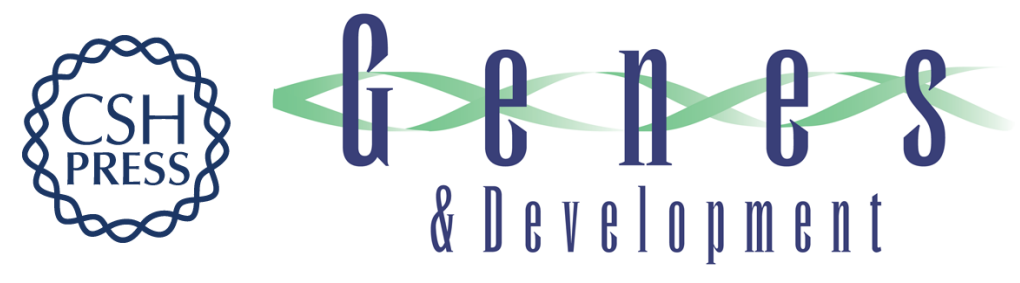

\section{Mammalian sex determination: a molecular drama}

Amanda Swain and Robin Lovell-Badge

Genes Dev. 1999, 13:

References This article cites 88 articles, 29 of which can be accessed free at: http://genesdev.cshlp.org/content/13/7/755.full.html\#ref-list-1

License

Email Alerting

Receive free email alerts when new articles cite this article - sign up in the box at the top Service right corner of the article or click here.

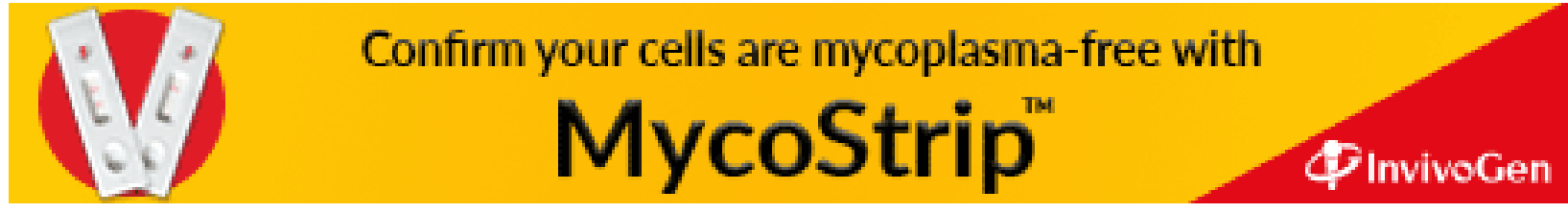

